\title{
Formation of local immunity in infants on different types of feeding
}

\author{
Tatyana Borodulina ${ }^{1 *}$, Natalia Sokolova ${ }^{1}$, Natalia Sannikova ${ }^{1}$, and Tatiana Martynova ${ }^{1}$ \\ ${ }^{1}$ Ural State Medical University, Faculty of pediatrics, 620028, Yekaterinburg, Russia
}

\begin{abstract}
Rational feeding from the early days of life programs the health, growth and development of the child over the following years. By the age of 6 months children on artificial feeding are reliably more likely to form excess body weight. The nature of nutrition depends on the condition of the overall and local immune protection of the child. Application of non-invasive methods for determining sIgA (in oral fluid (saliva), in coprofiltrate) allows to assess local immunity in infancy age. Breastfed infants receive $\operatorname{sg}$ A with mother's milk and have additional protection against the pathogens of respiratory and intestinal infections. The level of $\operatorname{sIg} \mathrm{A}$ in the mother's breast milk can be determined to assess the condition of children's immunity. Children on breastfeeding experience acute respiratory diseases less often compared to children fed with adapted milk formula.
\end{abstract}

\section{Introduction}

Rational feeding from the early days of life programs the health, growth and development of the child over the following years [1]. The nature of nutrition depends on the condition of the overall and local immune protection of the child. It is known that in the first 6 months of life child's immune system is immature, in this period breast milk is of great importance for the immune response formation; breast milk contains non-specific protection factors: immunogolobulins, lactoferrin, lysozyme, interferon, etc. [2, 3]. Immunoglobulins of mother's milk and mainly secretory immunoglobulin A (sIgA) protect mucous membranes of the gastrointestinal tract from being populated by pathogens and viruses, contribute to the formation of normal intestine microflora $[4,5]$.

In turn, a special role in the formation of local immunity belongs to the intestine microflora which activates the sIgA synthesis by plasmic and epithelial cells of the intestine [6]. Thus, the main role of $\operatorname{sg} \mathrm{A}$ is the local mucous membranes immunity; it prevents the attachment and penetration of microorganisms and viruses through mucous membranes epithelium with pathogens binding, as well as neutralizing viruses within epithelial cells [7].

To assess infants local immunity, non-invasive methods of siGA determination are used: in oral fluid (saliva) and coprofiltrate [8,9]. The immunoenzyme analysis (IEA) method is used to determine the amount of siGA.

\footnotetext{
* Corresponding author: tborodulina@ mail.ru
} 
Determination of siGA level in oral fluid (saliva) is used to assess local mucosal immunity in infants and can be used to dynamically monitor the condition of children's immune system [8].

Earlier studies have shown positive experience in determining siGA in coprofiltrate. It has been proven that the number of $\operatorname{sgA}$ is higher in coprofiltrates of breastfed children compared to those on artificial feeding [10]. This is because breastfed infants receive sIgA with mother's milk, thereby having additional protection against intestinal, respiratory and urinary infections [11]. In turn, the state of infant's immunity can be indirectly judged by the sIgA level in mother's breast milk [12].

Thus, the state of local immunity is an important determinant of children's health in the first year of life.

The purpose of the study is to assess the health and state of local immunity in children of the first 6 months of life fed with breast milk or bottlefed.

\section{Materials and Methods of Research}

The study was conducted on the basis of the children's polyclinic of the state budgetary institution of health of Sverdlovsk oblast "Beryozovsky Central City Hospital" ( Berezovsky) using selective continuous method. Open comparative prospective study.

\section{Study participants}

The study involved children from the first six months of life between the ages of 5-7 days and 6 months $(n=140)$. A prerequisite for participation in the study was signing the voluntary informed consent by parents (legal representatives).

Criteria for children inclusion in the study were: gestational age 37-42 weeks; absence of the central nervous system organic pathology, hereditary and genetic diseases, congenital metabolic disorders, HIV.

Criteria for children exclusion from the study: children with birth weight less than 2,500 g; mixed feeding; congenital metabolic disorders; hereditary and genetic diseases; organic lesions of the central nervous system; HIV.

The examined children were divided into two groups: group I $(n=70)$ - exclusively breastfed children (girls - 48\%, boys - 52\%); group II ( $=70)$ - artificial feeding with adapted milk formula (girls - 54\%, boys - $46 \%$ ).

All children were given a comprehensive health assessment on a monthly basis. Physical development was assessed using WHO international standards (ANTHRO 3.2.2). Z-score value was calculated for body weight in relation to body length, body weight relative to age, length and body weight index relative to age.

In nursing mothers $(n=30)$, we investigated the composition of breast milk in the period of 3 months in lactation with determinining the sIgA level by the solid-phase heterogeneous IEA method using "Vector-Best" test systems (Russia, Novosibirsk). In parallel, the sIgA level in coprofiltrate was determined by the solid-phase heterogeneous IEA method using "Vector-Best" test systems (Russia, Novosibirsk).

The laboratory studies results are presented in units of the international SI system and processed by variational statistics methods. The arithmetic mean (M), standard deviation $(\sigma)$, standard error $(\mathrm{m})$ were calculated. The Siudent criterion was used in assessing the differences validity, and the criterion $\mathrm{x}^{2}$ (chi-square) for traits with non-parametric distribution. Only results with a reliable level of difference $(p<0.05)$ were taken into account in the correlation analysis. Mathematical processing was performed on the Intel ${ }^{\circledR}$ Pentium ${ }^{\circledR} 4$ personal computer using STATISTICA13.3. 


\section{Results and discussion}

Antenatal period development analysis allowed to identify the complicated course of pregnancy in $70 \%$ of women (abortion - 35.7\%, pregnancy regress - 9.3\%, miscarriage $-10.7 \%$, gestosis $-41.4 \%$, anemia $-43.6 \%$, threat of pregnancy termination $-33.6 \%$, chronic fetoplancental insufficiency - 52.1\%). Most infants were born as first or second pregnancies $(62.2 \%)$, first births - $(45.7 \%)$. Body length and weight at birth are shown in Table 1.

Table 1. Characteristics of anthropometric indicators of children at birth

\begin{tabular}{|l|l|l|}
\hline Anthropometrical indicators & group I $(\mathrm{n}=70)$ & group II $(\mathrm{n}=70)$ \\
\hline Body weight, $\mathrm{g}$ & $3430 \pm 0.406$ & $3350 \pm 0.412$ \\
\hline Body length, $\mathrm{cm}$ & $52.3 \pm 2.1$ & $52.1 \pm 1.99$ \\
\hline Head circumference, $\mathrm{cm}$ & $34.3 \pm 1.29$ & $34.2 \pm 1.3$ \\
\hline Thorax circumference, $\mathrm{cm}$ & $33.4 \pm 1.55$ & $33.3 \pm 1.56$ \\
\hline
\end{tabular}

Analysis of anthropometric indicators during the first 6 months of life showed that in both groups the physical development of most children corresponded to real age, but children of the second group had increased body weight relative to age and body length, body mass index $(\mathrm{BMI})$ relative to age $(\mathrm{p}<0.05)$ (table 2$)$ was significantly more likely to be determined by age 6 months.

Table 2. Z-score indicators in examined children, abs.no. (\%)

\begin{tabular}{|c|c|c|c|c|}
\hline \multirow[t]{2}{*}{ Z-score } & \multicolumn{2}{|c|}{ group I $(n=70)$} & \multicolumn{2}{|c|}{ group II $(\mathrm{n}=70)$} \\
\hline & 1 month & 6 months & 1 month & 6 months \\
\hline & 1 & 2 & 3 & 4 \\
\hline \multicolumn{5}{|c|}{ Body length relative to age } \\
\hline$<-2$ & $2(2.9)$ & $2(2.9)$ & - & - \\
\hline$-1--2$ & $7(10)$ & $5(7.1)$ & $6(8.6)$ & $13(18.6) * * * *$ \\
\hline \pm 1 & $38(54.3)$ & $44(62.8)$ & $50(71.4) * * *$ & $40(57.1) * *$ \\
\hline$+1-+2$ & $18(25.7)$ & $12(17.1)$ & $12(17.1)$ & $14(20)$ \\
\hline$>+2$ & $5(7.1)$ & $7(10)$ & $2(2.9)$ & $3(4.3)$ \\
\hline \multicolumn{5}{|c|}{ Body weight relative to body length } \\
\hline$<-2$ & $2(2.9)$ & $1(1.4)$ & $5(7.1)$ & - \\
\hline$-1--2$ & $11(15.7)$ & $5(7.1)$ & $12(17.1)$ & $5(7.1)$ \\
\hline \pm 1 & $50(71.4)$ & $51(72.9)$ & $43(61.4)$ & $42(60)$ \\
\hline$+1-+2$ & $7(10)$ & $12(17.1)$ & $8(11.4)$ & $21(30)$ \\
\hline$>+2$ & - & $1(1.4)$ & $2(2.9)$ & $2(2.9)$ \\
\hline \multicolumn{5}{|c|}{ Body weight relative to age } \\
\hline$<-2$ & $2(2.9)$ & - & $2(2.9)$ & $1(1.4)$ \\
\hline$-1--2$ & $9(12.9)$ & $6(8.6)$ & $11(15.7)$ & $5(7.1)$ \\
\hline \pm 1 & $46(65.7)$ & $50(71.4)$ & $53(75.7)$ & $43(61.4)$ \\
\hline$+1-+2$ & $12(17.7)$ & $12(17.1)$ & $4(5.7) * * *$ & $19(27.1)^{* *}$ \\
\hline$>+2$ & $1(1.4)$ & $2(2.9)$ & - & $2(2.9)$ \\
\hline \multicolumn{5}{|c|}{ Body weight index relative to age } \\
\hline$<-2$ & $1(1.4)$ & $1(1.4)$ & $5(7.1)$ & - \\
\hline$-1--2$ & $7(10)$ & $6(8.6)$ & $9(12.9)$ & $7(10)$ \\
\hline \pm 1 & $56(80)$ & $50(71.4)$ & $52(74.3)$ & $40(57.1) * *$ \\
\hline$+1-+2$ & $5(7.1)$ & $12(17.1)$ & $4(5.7)$ & $21(30)^{* *}$ \\
\hline$>+2$ & $1(1.4)$ & $1(1.4)$ & - & $2(2.9)$ \\
\hline
\end{tabular}

$* 1: 2 \mathrm{p}<0.05 ; * * 3: 4 \mathrm{p}<0.05 ; * * * 1: 3 \mathrm{p}<0.05 ; * * * * 2: 4 \mathrm{p}<0.05$ 
Analyzing the growth dynamics of children during the first 6 months of life, it was identified that children of the first and second groups did not differ at birth: average body weight and body length were almost the same, but noticeable differences have been determined in 1 month age. The body length of exclusively breastfed children was determined within the mean values $(53.4 \%)$ or was higher than the average of the reference population $(32.8 \%)$ and the body length of most children on artificial feeding was within the average values of the reference population $(71.4 \%, \mathrm{p}<0.05)$. The body weight relative to the length of 1 month age in most children of the first group (71.4\%) corresponded to the average values of the reference population, in the second group the conformity to the reference population was observed in $61.4 \%$ of children, and the number of overweight children was $14.3 \%$.

During the first 6 months of life, excess increases in body weight $(30 \%, \mathrm{p}<0.05)$ and body mass index $(32.9 \%, \mathrm{p}<0.05)$ relative to age in the group of children receiving adapted milk mixtures occured more frequently. There was no credible increase in body mass index for 6 months in the group of breastfed children.

Thus, children on artificial feeding are more likely to form excess body mass by the age of 6 months.

Determination of sIgA level in breast milk allowed to identify a decrease in its quantity in $10 \%$ of mothers, the average sIgA was $283 \pm 97.1 \mathrm{mg} / \mathrm{L}$. In other lactating mothers, sIgA level was determined to be more than $400 \mathrm{mg} / \mathrm{l}$. Apparently, decreased sIgA in breast milk is associated with the presence of adverse factors during pregnancy. Thus, the decrease of secretory immunoglobulin in milk was influenced by the following factors: women over 30 years old; repeated birth; presence of chronic pathology.

According to literary data, the immunological composition of breast milk is also influenced by the country of residence, diet, smoking, persistence of infections cytomegalovirus infection in particular [13 - 16].

To assess local immunity in children of the first 6 months of life, coprofiltrate sIgA was determined. We have established statistically reliable low sIgA values in coprofiltrate in children on artificial feeding in comparison to breastfed children (Table 3).

Table 3. SIgA level in coprofiltrate in children up to 6 months of age

\begin{tabular}{|l|c|c|c|c|}
\hline & group I $(\mathrm{n}=70)$ & group II $(\mathrm{n}=70)$ & \multicolumn{2}{|c|}{ Petra A.M.J. Scholtens, 2010 } \\
\cline { 4 - 5 } & & & BF children & AF children \\
\hline sIgA, mg/l & $443.63 \pm 278.55$ & $184.57 \pm 127.09$ & 767 & 449 \\
& $\sigma=54.62$ & $\sigma=28.43$ & $\mathrm{mg} / \mathrm{l}$ & $\mathrm{mg} / \mathrm{l}$ \\
\hline
\end{tabular}

During the period of 6 months observation, acute infectious disease was dominated by respiratory diseases, the most common were acute respiratory infections (rhinitis, rhinopharyngitis) (Table 4).

Table 4. Frequency of infectious diseases occurence

\begin{tabular}{|l|c|c|}
\hline Diseases & group I (n=70) & group II (n=70) \\
& Abs. number (\%) & Abs. number (\%) \\
\hline ARI: & & $45(64.3)$ \\
$1-2$ times & $34(48.6)$ & $9(6.4)$ \\
\hline 3 times & $5(3.6)$ & $6(4.3)$ \\
\hline Bronchitis & - & $4(2.9)$ \\
\hline Enterocolitis & $1(0.7)$ & $4(2.1)$ \\
\hline Tubootitis & - & \\
\hline
\end{tabular}


Breastfed children experienced an acute respiratory infection more easily and less frequently than children who received adapted milk formula. It was also found that acute bronchitis and acute tubootitis were reported only in children on artificial feeding.

During the first six months of life, $40 \%$ of exclusively breastfed children and $11.4 \%$ $(p<0.05)$ of children receiving adapted milk formula had no diseases.

Most children in the first and second groups had a second health group by the age of 6 months ( $97 \%$ and $95 \%$ respectively).

\section{Conclusions}

Thus, the study allowed to identify the influence of different feeding types on the physical development and health of children - particularly on infectious morbidity of children of the first 6 months of life.

Breast milk provides not only a full need for basic macro and micronutrients of children in the first months of life, but also creates a foundation for non-specific immunological resistance. Due to exogenous receipt of secretory immunoglobulin with breast milk to breastfed children, there is an increase in the sIgA content in the coprofiltrate of these children; thus, breastfeeding positively affects the formation of local immunity and contributes to increased resistance of the child's body.

\section{References}

1. N. E. Sannikova, T. V. Borodulina, L. N. Malyamova, Questions of modern pediatrics, 13 (4), 140-144 (2014)

2. B. J. Stephen, N. Pareek, M. Saeed, M. A. Kausar, S. Rahman, M. Datta, Front Immunol., 24 (11) 404 (2020)

3. E. I. Kondratieva, D. E. Khapacheva, A. I. Tlif, L. A. Podporina, S. V. Storozhuk Questions of modern pediatrics, 12 (1), 172-176 (2013).

4. V. P. Dunne-Castagna, D. A. Mills, B Lönnerdal, Nestle Nutr Inst Workshop Ser., 94, 158-168 (2020)

5. Y. N. Dementieva, Russian Journal of Perinatology and Pediatrics, 4, 19-24 (2015)

6. E. P. Kiseleva, Infection and immunity, 5 (2), 113 - 130 (2015)

7. O. V. Moskalets, Kazan Medical Journal 98 (5), 809-815 (2017)

8. E. V. Matveeva, T. I. Legon'kova, O. V. Voitenkova, O. N. Shtykova, Herald of Smolensk State Medical Academy, 15 (2), 32-35 (2016)

9. K. P. Shamova, L. S. Ustyantseva, Medical Immunology "Days of Immunology in St. Petersburg 2017", Content of secretory IgA in coprofiltrates in children with extreme low body weight in postnatal period, 250-251 (2017)

10. L. Xiao, C. Gong, Y. Ding, G. Ding, X. Xu, C. Deng, X. Ze, P. Malard, X. Ben, Benef Microbes. 10 (7),729-739 (2019)

11. L. S. Nolan, O. B. Parks, M. Good, Nutrients, 12 (1) (2019)

12. C. C. Ellberg, K. Sayler, L. C. Hibel, Dev Psychobiol., 62 (4), 544-553 (2020)

13. D. B. Munblit, A. I. Borushko, M. S. Treneva, A. N. Pampura. Pediatrics, 95 (4), 104109 (2016)

14. M. Kuitunen, A. K. Kukkonen, E. Savilahti. Int. Arch. Allergy. Immunol., 159 (2), 162$170(2012)$

15. L. Orivuori, G. Loss, C. Roduit, et al. Clin. Exp. Allergy, 44 (1), 102-112 (2014)

16. H. J. Urwin, E. A. Miles, P. S. Noakes, et al. J. Nutr.,142 (8), 1603-1610 (2012) 
17. Petra A.M.J. Scholtens, Philippe Alliet, Marc Raes, Martine S. Alles, Hilde Kroes, Gaenther Boehm, Leon M.J. Knippels, Jan Knol, Yvan Vandenplas. Pediatrics, 89 (6), 83-91 (2010) 